6. Wachter DA, Joshi MP, Rimal B. Antibiotic dispensing by drug retailers in Kathmandu, Napal. Trop Med Int Health 1999; 4:782-788.

7. Van Duong D, Binns CW, Van Le T. Availability of antibiotics as overthe-counter drugs in pharmacies: a threat to public health in Vietnam. Trop Med Int Health 1997; 2:1133-1139.

8. Volpato DE, de Souza BV, Della Rosa LG, et al. Use of antibiotics without medical prescription. Braz J Infect Dis 2005; 9:288-291.

9. Nyazema N, Viberg N, Khoza S, et al. Low sale of antibiotics without prescription: a cross-sectional study in Zimbabwean private pharmacies. J Antimicrob Chemother 2007; 59:718-726.

10. Gül H, Omurtag G, Clark PM, Tozan A, Özel S. Nonprescription medication purchases and the role of pharmacists as healthcare workers in self-medication in Istanbul. Med Sci Monit 2007; 13:PH9-PH14.

\section{Measuring Hand Hygiene Compliance: A New Frontier for Improving Hand Hygiene}

Hand hygiene practices are suboptimal in clinical venues, and improving and sustaining rates of compliance have been difficult to achieve. ${ }^{1}$ Feedback to clinicians has been recognized as a mechanism for improving compliance. ${ }^{1,2}$ Rarely are healthcare workers provided with personalized feedback on their hand hygiene practices. Electronic technology is being explored as a means to improve the rates of hand hygiene compliance. ${ }^{3}$ This emerging area of study has the potential to provide an important level of necessary feedback and to serve as a critical tool for improving hand hygiene practices.

We have developed a device that operates similarly to the way a pedometer operates, by providing feedback data to an individual who wishes to quantify his/her level of activity. The basis for this device stems from the use of room entries and the use of liquid soap or hand sanitizer (hereafter referred to as dispensing events) as surrogate markers for hand hygiene compliance. Each patient room entry constitutes 2 opportunities for hand hygiene ( 1 before patient or environmental contact and 1 after).

This device is small (size, $8 \mathrm{~cm} \times 3 \mathrm{~cm} \times 1 \mathrm{~cm}$ ) and can therefore be conveniently placed in one's pocket. It is eapable of recording each room entry and all dispensing events by use of wireless technology. Small trigger devices are placed discreetly in patient rooms and in dispensers to signal room entries and hand hygiene events. The device maintains a small LCD monitor readout that provides the user with real-time data on room entries and dispensing events with a calculated score. The data from the device are downloaded by use of a USB computer port and accessed by use of a Windows application. The data are recorded and displayed anonymously, with each device assigned a specific identification number. We have conducted preliminary testing of the device and have found it to be accurate and reliable. Of 425 room entries, $423(99.5 \%)$ were recorded; of 678 dispensing events, 626 $(\mathbf{9 2 . 3} \%)$ were recorded.

We will be conducting a second phase of our study to test the effectiveness of the device in a clinical setting. Healthcare workers will be provided with the device, which will be worn during daily clinical encounters with patients. Participants will be able to view their data as well as those of all other study participants (anonymously) at weekly intervals. Such a mechanism would allow for users to compare themselves with others. By the use of this reliable and accurate objective measure of hand hygiene compliance, we hope to achieve behavioral modification by providing feedback to healthcare workers.

\section{ACKNOWLEDGMENTS}

Potential conflicts of interest. All authors report no conflicts of interest relevant to this article.

Andrew G. Sahud, MD; Nitin Bhanot, MD, MPH

From the Division of Infectious Diseases, Allegheny General Hospital, Pittsburgh, Pennsylvania (both authors).

Address reprint requests to Andrew G. Sahud, MD, Division of Infectious Diseases, Allegheny General Hospital, 320 East North Avenue, South Tower, Pittsburgh, PA 15212 (asahud@wpahs.org).

Infect Control Hosp Epidemiol 2009; 30:1132

(C) 2009 by The Society for Healthcare Epidemiology of America. All rights reserved. 0899-823X/2009/3011-0021\$15.00. DOI: 10.1086/647979

\section{REFERENCES}

1. Pittet D. Improving compliance with hand hygiene in hospitals. Infect Control Hosp Epidemiol 2000; 21:381-386.

2. McGuckin M, Waterman R, Govednik J. Hand hygiene compliance rates in the United States-a one-year multicenter collaborative using product/volume usage measurement and feedback. Am J Med Qual 2009; 24: 205-213.

3. Fries J, Hlady C, Herman T, et al. A low-cost non-RFID based method for automated monitoring of hand hygiene compliance. In: Program and abstracts of the 19th Annual Scientific Meeting of the Society for Healthcare Epidemiology of America. March 19-22, 2009; San Diego, CA. Abstract 123.

\section{Influenza Pseudoinfection}

We read the article by Shulze-Röbbeke and Schmitz on pseudoinfections. ${ }^{1}$ Pseudoinfections are interesting and present a diagnostic challenge. ${ }^{1}$ Differing from a misdiagnosis of infection resulting from contaminants or laboratory errors, pseudoinfections occur when the clinical presentation and laboratory findings disagree..$^{2-4}$ Recently, a patient was admitted to the emergency department with an influenza-like illness. The result of a rapid influenza test (QuickVue; Quidel) was positive for influenza A virus, and appropriate isolation precautions were taken. However, the clinical findings did not support the 
laboratory test diagnosis. We believe that this case of influenza pseudoinfection illustrates several important points. ${ }^{2-4}$

The patient, a 19-year-old man, presented with a 4-day history of fever (temperature, greater than $39^{\circ} \mathrm{C}\left[102^{\circ} \mathrm{F}\right]$ ), chills, headache, and myalgias. His illness began suddenly and was accompanied by profound fatigue. He denied any recent known contact with sick people or any recent travel. He had not received the influenza vaccination. Just prior to emergency department admission, he noted that he had a sore throat and a faint generalized rash.

On physical examination, he seemed exhausted and in moderate distress, and his temperature was $39^{\circ} \mathrm{C}\left(102^{\circ} \mathrm{F}\right)$. Conjunctival suffusion was present, and his pharynx was mildly erythematous without exudates. His posterior neck muscles were tense and sore and had limited range of motion. The results of cardiac and abdominal examinations were unremarkable. He had a faint maculopapular rash on his distal extremities that blanched with pressure. His rash extended to the chest and abdomen. While the patient was in the emergency department, a rapid influenza test was performed, and after 10 minutes, the result was interpreted as positive for influenza A virus. Appropriate isolation precautions were taken. His condition improved after analgesics were administered and adequate hydration was maintained. Because rash is not a clinical feature of influenza, a second rapid influenza test was performed and interpreted after 10 minutes. The result of the second test was interpreted as equivocal because the band (positive test indication) showed a very faint reaction for influenza A virus. Elsewhere, Quach et al and Ruest et al have reported faintly positive reactions when the rapid influenza test result is interpreted after 10 minutes. ${ }^{5,6}$ To sort out the variable rapid influenza test results (ie, a positive test result and then an equivocal test result), a direct respiratory fluorescent antibody viral panel test of the nasopharynx was performed, as well as viral cultures. Before the results of the latter tests were available, the patient received a diagnosis of influenza A virus infection and was discharged from the hospital. Subsequently, the results of the direct respiratory fluorescent antibody viral panel test and the viral culture were reported as positive for adenovirus (not typed).

To our knowledge, this is the first report of influenza pseudoinfection, and we believe that it illustrates several important points. The patient presented with clinical findings consistent with influenza. He presented during influenza season and had not received the influenza vaccination. However, the clinical feature that argued strongly against the diagnosis of influenza was his rash.' The other diagnostic problem resulted from the interpretation of his rapid influenza tests. The initial rapid influenza test result was positive when interpreted after 10 minutes, but the second test result, although reactive, was faint and interpreted as equivocal at 10 minutes. The manufacturer's instructions for the rapid influenza test recom- mend that the test be read at 10 minutes (most reactions become positive before 10 minutes). This case serves as a reminder that if laboratory and clinical findings are contradictory, clinical findings should take precedence; in this case, the correct diagnosis was adenovirus. ${ }^{8}$

Rapid influenza tests performed in the emergency department have been of inestimable value in making correct decisions regarding triage, isolation, and therapy. When such point-of-care rapid tests are used, instructions should be carefully followed. The clinical presentation was consistent with influenza, except for a rash, but adenovirus may have many of the same findings as influenza. Without the rash, influenza retesting would not have been performed, and influenza pseudoinfection would not have been recognized.

\section{ACKNOWLEDGMENTS}

Potential conflicts of interest. All authors report no conflicts of interest relevant to this article.

Burke A. Cunha, MD; Paul J. Lee, MD; Francisco M. Pherez, MD

From the Infectious Disease Division (B.A.C., F.M.P.) and the Pediatric Infectious Disease Division (P.J.L.), Winthrop-University Hospital, Mineola, and State University of New York School of Medicine, Stony Brook (B.A.C.), New York.

Address reprint requests to Burke A. Cunha, MD, Infectious Disease Division, Winthrop-University Hospital, Mineola, NY 11501.

Infect Control Hosp Epidemiol 2009; 30:1132-1133

(C) 2009 by The Society for Healthcare Epidemiology of America. All rights reserved. 0899-823X/2009/3011-0022\$15.00. DOI: 10.1086/647983

\section{REFERENCES}

1. Schulze-Röbbecke R, Schmitz C. Pseudoinfection due to mislabeling. Infect Control Hosp Epidemiol 2009; 30:408.

2. Cunha BA. Pseudoinfections and pseudo-outbreaks. In: Mayhall GC, ed. Hospital Epidemiology and Infection Control. 3rd ed. Philadelphia, PA: Lippincott Williams \& Wilkins; 2004:123-133.

3. Weinstein RA, Stamm WE. Pseudoepidemics in hospital. Lancet 1977; 2: 862-864.

4. Manangan LP, Jarvis WR. Healthcare-associated pseudo-outbreaks. Semin Infect Control 2001; 1:102-110.

5. Quach C, Newby D, Daoust G, Rubin E, McDonald J. QuickVue influenza test for rapid detection of influenza $A$ and $B$ viruses in a pediatric population. Clin Diagn Lab Immunol 2002; 9:925-926.

6. Ruest A, Michaud S, Deslandes S, Frost EH. Comparison of the Directigen flu $A+B$ test, the QuickVue influenza test and clinical case definition to viral culture and reverse transcription-PCR for rapid diagnosis of influenza virus infection. J Clin Microbiol 2003; 41:3487-3493.

7. Cunha BA. The clinical diagnosis of severe viral influenza A. Infection 2008; 36:92-93.

8. Cunha BA. The diagnosing mind: the diagnostic significance of non-specific laboratory tests. Winthrop-University Hosp Med J 2006; 28:489-493. 